\title{
The collector
}

\section{How Paddy Patterson, one of the architects of the Encyclopedia of Life, hopes to present biodiversity to the world.} \begin{abstract}
off small, working on the taxonomy of protists and protozoa and putting descriptions of them up on the web in macro in a big way with the Encyclopedia of Life (EOL), a project that intends to create a website for every known species on Earth.

So what is the proposed schedule for the EOL? In February next year, hopefully, there will be a major release of the first edition of the EOL. The expectation is that within a ten-year period we will have relatively well-informed pages on all 1.8 million species.
\end{abstract}

David 'Paddy' Patterson started his career projects such as Micro*scope, Microbial Life and the International Census of Marine Microbes. Now, the biologist, who works in Woods Hole, Massachusetts, is going

\section{How can you realistically hope to get} that much done?

The EOL will act like a glue to join together the information that is already out there on the Internet. We don't have to create 1.8 million pages. What we need to do is know where the information is that's out there on the species.

\section{How do you put it together?}

The usual solution is to try and find out what the correct name is for a species and then try to get all the databases to apply the correct name. But names are always changing as a result of taxonomic research.

We adopted a different solution, which we call reconciliation. What we do is tap into the accumulated knowledge of taxonomists and draw together their understanding of all the different names that have ever been used for an organism, and extend this to cover typographical errors, vernacular names, and any name that might appear in a document that is online or a database that is online.

We've built the system so that you can have any browsing structure in place. So if you want to change from the hierarchy provided by the Catalogue of Life [an attempt to index all known species] to that the community we would most like to see develop a better understanding of biodiversity and how biodiversity came about.
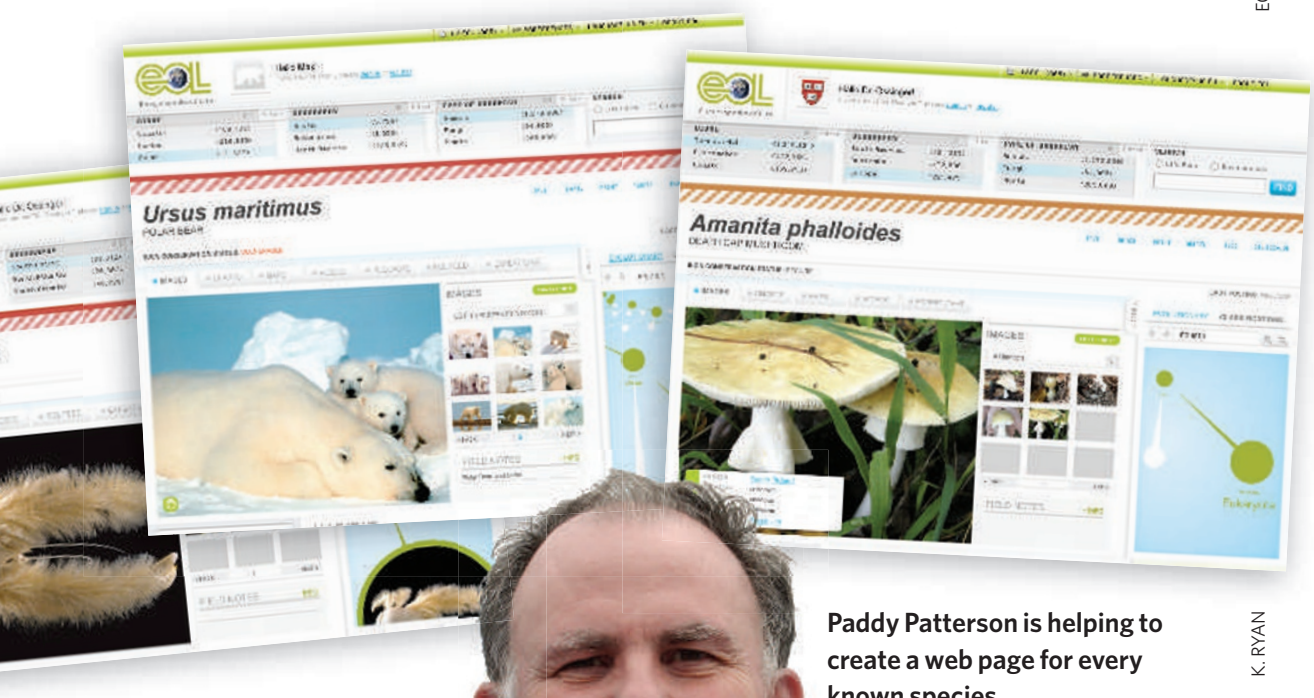

provided by GenBank [a database of all published DNA sequences], you just click on the alternative classification.

How far should that flexibility extend? You previously mentioned making room for an intelligent-design perspective on the EOL?

Many bits of the EOL still need to be resolved, but one of the features of the EOL is that it has to be a highly flexible, very personalizable environment. If the EOL is to fulfil the role that we think it should fulfil, then students at high school should see something different from, for example, what a research scientist sees. Similarly, people visiting from Pakistan should be able to see the content in a language that suits them and is not culturally offensive to them.

And the same thing is true, I think, of people who hold beliefs such as intelligent design or the creationist argument. It would be, in my view, a great failing if we created an environment that they found offensive and were unwilling to enter. They are, after all, probably create a web page for every known species.

That sounds like a controversial approach? It was. Plenty of people would have me hung up by my whatever-it-was for this. My view is that by giving the stage to this community, what they're thinking becomes open to wider scrutiny. Instead of talking in closed churches, now the public can see the extent of their thinking. I see it as something that should improve the knowledge environment in general.

You're obviously very keen on involving people in the project as widely as possible?

Some of the features we're developing will be rather like wikis or the social networking software out there. One of the things I would love to see develop early on is a 'my schoolyard' function in which kids can go outside with cell phones and take pictures of organisms and submit them to the EOL. There, the pictures are sent off to experts who verify identification. And when that is done, a little dot appears on Google Earth showing the presence of, say, a daffodil in someone's backyard.

Interview by Brendan Maher. 